\section{PORNOGRAPHY A SUBSTITUTE FOR PROSTITUTION: KEYS TO DEAL WITH MALEVOLENCE}

\author{
M.Sc. Students, School of Behavioural Science, \\ National Forensic Sciences University \\ Gandhinagar, Gujarat. \\ rashib1911@gmail.com, \\ M.Sc. Students, School of Behavioural Science, \\ National Forensic Sciences University \\ Gandhinagar, Gujarat. \\ chhabrav2112@gmail.com
}

Rashi Bhakta, Vandana Chhabra, Dr. Priyanka Kacker

Senior Assistant Professor, School of Behavioural Science,

National Forensic Sciences University, Gandhinagar, Gujarat.

priyanka.kacker@nfsu.ac.in

\begin{abstract}
This paper aims to explore if prostitution can be replaced by pornography. Pornography is easily accessible in today's time to each and every one without discrimination. It is available to people of all gender and age groups. Prostitution involves real people while pornography involves actors in recorded setup. There is a wide spread notion that pornography is an art form but what do artists and historians along with common people feel. This paper also aims to draw an outline as to what is considered normal sexual activity/action, crime or pathology. Prostitution can help in reduction of rape while pornography can help in release of sexual urges in a healthy way, then why is it considered as a toxic and corrupting sector. The paper also suggests suggestions of how pornography can be used as healthy yet a secured way to deal with Malevolence to take care of mental health as well as the increase of crime rate due to one of the basic physical needs.
\end{abstract}

Keywords: Pornography, Prostitution, Substitution, Secured, Obscene.

\section{INTRODUCTION}

Sexual experiences involve the deepest corners of ourselves and are among the most intense, powerful, emotional, and profound experiences we have. (Maes, 2012). But still activities related to this experience are often viewed under negative light. This paper aims at discussing why pornography and prostitution are considered as the activity labeled immoral and tainting one's character.

\section{Pornography as a substitute for Prostitution}

Pornographic content can easily be accessed online at the click of a button. Technological advances have made it available to people of all genders and age groups however it is banned in India as the Indian directed internet service providers to block 827 websites following Uttarakhand high court order. But it is still available to the people by mere installation of another app for VPN or proxy (Pathak, P. India Today, 2018). However despite the ban, in 2019, 89\% Indians still watched pornographic content online. India has the leading consumption of porn in the world (CNBC-TV18, 2020). But can it be assumed that pornography is a substitution of prostitution owing to the easy accessibility and availability of the former to individuals of all age genders?

In the situation where $A$ and $B$ are two adults and $A$ and $B$ indulge in sex in following scenarios:

(1) A and B had sex because B paid A for it

(2) A and B had sex because a third party paid them to have sex to make porn

In the first scenario, A committed the crime of prostitution, on the other hand in the second scenario no such thing happened as per a lot of countries.

Despite the similarity in the both situation A is paid to have sex and A has no romantic feelings towards B then why do we consider that a crime has occurred in first scenario while it didn't in the second.

The distinction between pornography and prostitution is a very fine one and comes down to a string of cases finding that porn performances actually constitute acting subject to the artistic expression protections of the First Amendment to the United States Constitution. Thus, the distinction is that, at least in theory, porn stars are paid to act and prostitutes are paid for sex. Hence pornography is legal while prostitution is not. 


\section{GAP INDIAN JOURNAL OF FORENSICS AND BEHAVIOURAL SCIENCES}

( ISSN - 2582-8177)

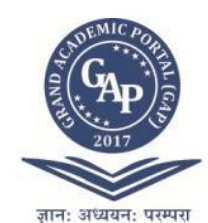

Folk Theory explains this deviation as a result of the combined effect of interaction among cultural commitment to satisfy the desires of the males and the cultural anxiety regarding the risks associated with getting sexually involved with a female directly. Men are considered supreme species in this male dominating society where the cultural believes place too much importance over satisfying the desires of males and prostitution and pornography both serve as means to that end. However since prostitution requires direct physical contact, it is believed that it might corrupt or taint the involving male contaminating them physically, socially and morally. While pornography on the other hand wont. This theory makes it very clear as to why the law of a lot of countries discriminate between the two.

A Prostitute is "an individual who indiscriminately provides sexual relations in return for money payments" (Kaye, 2016).

Prostitution is also perceived by some as a profession and an oldest one at that. The rationale behind this is that a fee is levied upon the people who use the professional services, it also helps differentiate prostitution from a romantic relationship as no explicit fee is imposed. But as per this understanding, pornography should also be considered as prostitution as a payment is made to engage in sexual activities. Generally, actors working in pornographic films aren't married, and the actors indulging in sex are doing so with complete professionalism and without any discrimination. On the basis of both the premises stated above, it can be concluded that pornography is a form of prostitution.

However Prostitution is a criminal offence in most of the countries while pornography is not and the laws criminalizing prostitution defy all rationale, progressiveness, and exist on the basis of superstitious belief that prostitutes taint the men and hence all mankind. Prostitutes in the eyes of such laws are seen as perpetrators of the crime and not as a victim. Sex needs to be accepted as a human need and liberalizing sex regulation is a necessity of the hour (Kaye, 2016).

\section{Pornography: Another form of Art and Culture}

A painting by Rembrandt titled 'Bathsheba in her Bath' shows a naked woman contemplating her situation where the king has asked her to come to palace and she understands that it will involve her sleeping with the king and deceiving her husband and she could see the destruction it will cause in her life. This painting has been argued to be the classic work of art focusing on minute emotions on the face of the woman ignoring her naked body while the same isn't said about the photos of naked women in magazines. (Maes, 2012)

However a lot of authors aim at establishing art and pornography as mutual exclusive and not related in any aspect which highly depends on the point of view of the spectator. Pornography and art can be distinguished on the basis of the following four ways (Maes, 2012):

1. Representational content: As the name suggests, it focuses on how the art and porn are represented or seen. Pornography revolves around sexual activities that are aggressive, emotionless or alienated while erotic art on the other hand is seen as signifying the love, equality between both the partners and passion. To justify this stance, rationale is taken from the etymology of the words. The term erotic art is taken from Greek word eros which means love or passion, signifying intimacy and sex as a result of love and affection individuals feel for each other. The root word of pornography is 'porne' which means dehumanized and emotionless sexuality. In their essay for the Langford committee on Pornography (1972) the famous authors Kingsley Amis and E.J. Howard recommended avoiding the usage of the term 'Love' in any and every pornographic work to avoid any confusion or misunderstanding.

2. Moral status: Stating that pornography is different from art on the basis of a particular content won't be enough to justify that pornography is immoral. It is often argued that Pornography contains sex that is emotionless and impoverished, but this argument can only justify that pornography lacks character and is vulgar, however it is not enough to label it as immoral. To point out the flaws of pornography the terms like 'objectification' and 'exploitation' are used. Nancy Spero had defined pornography as 'stuff that exploits women's bodies, and particularly in a harmful way'. These can help differentiate pornography from art on the premise that pornography exploits and objectifies unlike art.

3. Artistic quality: Following five arguments are generally put forward to establish that pornography lacks in artistic quality that works of art possess:

- Art is multidimensional, multifaceted and has many layers rolled into one while pornography is superficial and unidimensional. One cannot look for artistic interpretation when it comes to pornography unlike art.

- Artworks are generally novel and unique while pornography has the similar story revolving around the act of sex and copulation over and over again. The only purpose of a pornographer is to incite sexual desire and arousal which leaves very little room for development of plot, character or even climax. Since the number of sex positions and gestures is very limited, there is not much scope left for creativity.

- Porn films, photos and stories are generally produced on a large scale in the Porn Industry whereas art is a novel creation and not an industrial commodity.

- The prime focus of art revolved around beauty whereas pornography is considered indecent 


\section{$\stackrel{000}{=}$ \\ GAP INDIAN JOURNAL OF FORENSICS AND BEHAVIOURAL SCIENCES}

GRAND ACADEMIC PORTAL RESEARCH JOURNALS ( ISSN - 2582-8177)

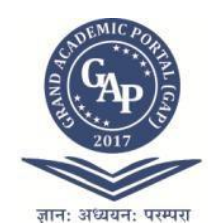

and lack aesthetics. Freud stated that 'the genitals themselves, the sight of which is always exciting, are hardly ever regarded as beautiful' (Van Alphen, 2005).

- Art is work of imagination while pornography relies on pure fantasy. The imagination of artists helps us in perceiving and making sense of the reality we live in whereas pornographers alter the reality to suit and virtually fulfil our desires and fantasies. Porn offers its users or viewers a different world, a realm where anything is possible, it is away from truth, reason and insight.

4. Prescribed response: Pornography is often viewed as anti-imaginative. Maes (2012) in his work has stated George Steiner's accusation on pornographers for doing the imagination on behalf of the audience and in the process not respecting the audience. However, if the aforementioned rationales are followed that numerous artworks will end up falling on the wrongful end of the distinction. The work of Bernardo Bertolucci (Last Tango in Paris) or Elfriede Jelinek's (The Piano Teacher) and many more focus on the aspect of sex that is violent and estranged instead of the one portraying love and equality between the parties involved. Also, not all art forms invite the audience for subjective interpretation.

On the other hand, a lot of features that are used to describe art are found in pornography as well. Movies like All about Anna, Novel titled That Kind of Girl etc are some of the examples of pornography that are no less than a work of art and can be grouped as the 'Female Friendly Pornography'. These works portray novel and creative scenarios focusing on beauty, and have the essence of real-life people in realistic scenarios. It focuses on the personality characteristics of female protagonists and their experiences. It is believed that such artworks are not flawed characteristically or morally, they don't exploit or objectify women, rather they portray feelings, passions, intimacy that are considered the distinctive characteristics of art. These works have rejected the oppression, repression or hypocrisy that revolved around sex and females, and thrown light on the concepts of female libido, desires, sexuality that have been neglected and blind-sighted by a lot of educationists and philosophers thereby educating and emancipating the audience.

These new works of pornography focusing on women, for women and made by women seem rather educating than immoral. Despite this, if such works are looked down upon, not considered as a form of art will lead to coarse mindsets that have stringent moral criteria for determining what is art making it the sole differentiating factor. Critics have often neglected to focus on the objectifying and exploiting aspects of erotic art, putting the works of art on an elevated pedestal that is beyond the bounds of morality.

The similar discrimination between considering certain erotic paintings as culture and not porn is seen in a few cultural references. The famous Khajuraho temple also known as the Kamasutra Temple is one such example of this discrimination.

The Kamasutra temple is an example of the conflicting ideals of the Indians, it is flourishing as a site of the open-mindedness and modernism in the travel and tourism sector of the country attracting various foreigners and elite classes of the country while on the other hand being criticized and damned for existing as an anecdote of the very contrast of culture and values of the country. It depicts pornography in the form of the scintillating and tantalizing sculptures which often are used to attract tourists by featuring them in the magazines and brochures developed by the ministry of tourism. The similar posters if developed by the porn industry is frowned upon labelling them as evil and corrupting the minds of youth while the Khajuraho's famous wall inscriptions and sculptures are even featured in the famous Incredible India campaign of the ministry with inconspicuous footnotes that appreciate these as depicting the honest and pure love. An example of such footnote printed in the Incredible India brochure of the State of Madhya Pradesh and the information Board of tourism read:

"Whatever the interpretation of the erotic scenes sculpted on the walls of the temples at Khajuraho, there is certainly nothing sordid or coarse about them. In fact, these representations have given us some of the finest sculptural compositions, which vibrate with a rare sensitivity and warmth of emotion."

However, the similar content if published with actual actors in a magazine or on internet sites, will be considered as pornographic content.

Khajuraho Temple is a contrast to the Indian culture, generally the temples are a place of worship held in high regard by the entire nation, whereas this particular temple is a site for erotica and desires that are hushed in societal talks. Famously referred to as the Kamasutra temple, it is a historical site for both pilgrimage and thrilling as it is not customary in a conservative society as India to be able to see such explicit content in public. The reason as to why such sculptures were carved in the walls of a temple is still ambiguous and no hard facts are written by Historians. These sculptures generally attract the foreign tourists more than Indians. One reason for it can be that such artistic representations are considered as immoral and toxic to humankind. But the same Indians visit these temples for the purpose of worshipping.

The year 2000 marked the completion of thousand years of the existence of Khajuraho temples. The tourism ministry organized the 'Khajuraho Millennium Bash' which lasted almost an entire year to mark the $1000^{\text {th }}$ anniversary of the temples. Annual dance festival is also organized every year where the dancers are invited 


\section{GAP INDIAN JOURNAL OF FORENSICS AND BEHAVIOURAL SCIENCES}

( ISSN - 2582-8177)

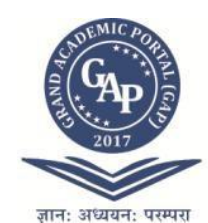

from all over the country to perform in front of the sculptures. The performances of these dancers are intimate portraying love and sensuality which is depicted as reenactment of the sculptures themselves depicting their significance as related to the past traditions. But similar pornographic content is looked down upon and justification on the basis of past traditions are discarded.

Usage of these erotic sculptures for promoting tourism industry is a little contradicting at the end of the government which talks about morality and immorality at such great lengths. Though the tags of immorality are conveniently placed on what is being identified as art or Indian. It can also depend on other premises as money, tradition and culture but mainly as a means to reaching desired ends.

The Supreme Court of the United States had put forward the Miller test in Miller vs California (1973) to legally describe Obscenity. It had put forward three criterias to define Obscenity:

1. It appears tempting to the immodest desires of a normal and average individual applying contemporary community standards.

2. It should involve sexual conduct that is offensive as recognized by the law of the land.

3. There should be absence of any value be it literary, artistic, scientific or political.

The Miller test's definition of obscene appears to have confused obscenity with pornography. One can state that obscenity does not include mere pornographic instances but it is bigger than that. The term includes any and every instance that can be offensive and is not just sexual in nature. It can be used to define anything that is a transgression, not just sexual, anything that is too much, or is considered a taboo or obscene art.

Differentiating between Disorder, Crime and Normal viewing of Sexual Content

Near Khajuraho Temple tourists are considered as voyeurs in public places. According to Laura Mulvey (1989) defined voyeurism as viewing an objectified female as an object of sexual stimulation through sight. In the sculptures there men and women are depicted as watching other couples in various sexual positions. The presence of these "peeping toms" in the sculptures appears to be an attempt to invite those who are gazing to join them in a collective voyeurism.But it cannot be considered a pathological disorder. To diagnose someone with Voyeuristic disorder the following criteria needs to be fulfilled (DSM-5 TR):

A. Over a period of at least 6 months, recurrent and intense sexual arousal from observing an unsuspecting person who is naked, in the process of disrobing, or engaging in sexual activity, as manifested by fantasies, urges, or behaviors.

B. The individual has acted on these sexual urges with a nonconsenting person, or the sexual urges or fantasies cause clinically significant distress or impairment in social, occupational, or other important areas of functioning.

C. The individual experiencing the arousal and/or acting on the urges is at least 18 years of age.

Recording Own selfshould (Not) Be Considered Crime

Michael Rea (2001) gave the 'no intimacy' requirement for something to be considered as porn. It is meant to rule out such things as the pictures or videos that a person might make for the private viewing pleasure of his or her spouse. Yet, one may wonder whether these should in fact be ruled out, given that there are plenty of internet guides for couples who want to experiment in this way, with titles ("Make your own porn film" / "Star in your own porn movie") that suggest that such home videos are commonly regarded as pornography. But the definition says otherwise. Homemade videos cannot be considered as porn because it requires the actors to be paid, who are not related generally and that it is an act.

Recording someone else Indulging Inthe Sexual Activity Can Be Considered as a Crime

Recording someone else indulging in sexual activities is a statement that implies it to be a crime if not looked at the entire context of it. Pornography is banned in India on the basis of the instances where individuals have raped someone claiming to be motivated for doing so by watching porn movies. But making pornographic films should not be considered as crime and is legal in most Latin American and European countries as stated in a 2014 article of The Indian Express. The laws regarding pornography have been altered in a few countries later on. Pornographic content involves recording someone else indulging sexual activities with explicit consent from all the parties involved. Any material that is recorded without the consent and explicit knowledge of any of the individuals involved can be considered as crime.

However recording someone indulging in any sexual activity without their consent and explicit knowledge is a crime be it acting or otherwise.

Defining Pornography

Pornography (sometimes the term sexually explicit material is used as a synonym [Downing,

Schrimshaw, Antebi, \& Siegel, 2014]), employing definitions that focus on two elements. The first is that pornography is "explicit" (Wright \& Randall, 2012) and includes "images of exposed genitals and/or depictions of sexual behaviors" (Morgan, 2011) that are "unconcealed" (Peter \&Valkenburg, 2011). The second is that pornography is "intended to increase sexual arousal" (Mckee, Alan \& Byron, Paul \&Litsou, Katerina \&Ingham, Roger, 2020)

Pornography is variably defined as the production. of sexual representation for the purpose of exchange. (Huer); artistic material with little, if any, aesthetic value. (Berger); the representation of persons as mere sexual objects (McElroy); [or] the representation of institutional.(Mckee, Alan \& Byron, Paul \&Litsou, Katerina \&Ingham, Roger, 2020) 


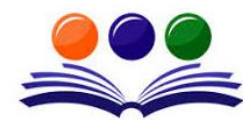 GRAND ACADEMIC PORTAL RESEARCH JOURNALS

$>$ Prostitution (buying and selling)

$>$ Strip clubs

$>$ Voyeurism

$>$ Exhibitionism, sexual harassment

$>$ Sexual offending

Therapists should also know that sex addicts only rarely engage in just one problematic behavior. The difference between addiction and non-addiction is non addicted individuals have the ability to stop their behavior and pull back, reestablishing control without external assistance, whereas addicts cannot.

With addiction of all types, clinicians typically see the following:

$>$ An obsession or preoccupation with obtaining, using or recovering from the behavior

> A loss of control, as exhibited by a persistent desire and/or unsuccessful efforts to curtail or stop use of the behavior

$>$ Continued use of the behavior despite adverse consequences.

The usage of pornography or prostitution and above mentioned sexual behaviors, when fit this criteria, can be diagnosed as an addiction.

\section{ADVANTAGES AND LIMITATIONS OF PROSTITUTION:}

When asked about the advantages and disadvantages of working in prostitution

\section{Advantages:}

Most of the women interviewed felt that the money was the main advantage, in addition to the flexible working hours and being their own boss. They could support their children and did not have to depend on a man to do so.

Prostitution can also help in reducing rape cases and sexual abuse. A paper published in American Economic Journal stated the Economic Policy by Bisschop, Kastoryano and van der Klaauw observed the areas known as tippelzones in several Dutch cities. The tipple zones are the zones where prostitution flourishes, also known as prostitution zones. It was seen that the numbers indicating sexual abuse and rape reduced significantly. In the initial two years the numbers reduced by $30-40 \%$. The opening of these tipple zones require license which further helped in the reduction of rape cases and assault and a $25 \%$ reduction was also observed in drug-use related crimes.

Riccardo Ciacci and Maria Micaela Sviatschi wrote a working paper which also saw and concluded that prostitution helped in the significant reduction of rape cases and other sex related crimes. To explore how the establishments housing indoor prostitution can affect rapes and sex crimes, they used a unique data set. From January 1, 2004 till June 30, 2012, for the period of 8 years a daily committee was developed which was given the exact opening and closing day of the indoor prostitution houses or buildings and the locations of the police stations that deal with the sex crimes. A reduction in rape cases and sex crimes was observed and it was concluded that since the customers who frequented the indoor prostitution were sex offenders, hence this change was observed. Other factors that could lead to reduction of sex crimes were also ruled out like increase in the number of police officers and the decrease of potential victims present in the concerned areas where the business of indoor prostitution was established. Additionally the results remained unchanged to various other sources of data and measures of sex crimes apart from the statistics reported in Police stops.

Another survey by Farley et al explored the number of men who paid women for sex in London. 54\% of these men reported that there would be higher chances of them raping a woman who is not a prostitute in absence of prostitution. It was then concluded that the people who are more likely to indulge in rapes and potential sex offenders would use indoor prostitution as a substitute (Ciacci and Sviatschi, 2016).

Hence, a wide range of evidence from different authors, times and places, and experiments credibly and clearly shows that that prostitution reduces rape. This finding is of great importance in considering how prostitution should be rationally regulated. (Tabarrok, 2017).

\section{Disadvantages:}

The main disadvantages of the job were "having to live a double life" and the fear of being "found out" "getting arrested and your name being on a record". They always thought that someone would recognize them or someone from their family, or peer group find out and know that they are into prostitution which will result into loss of self-esteem, feelings of shame and being degraded. They feared being arrested under the Sexual Offences Law, 1993. A certain number of women had experienced problems with clients; making them leave, being beaten up, being forced to have sexual contact. (0'Connor, 1996).

Janice G. Raymond of the Convention against Trafficking in Women (CATW), in her article, 127 stated that there are ten reasons for not legalizing prostitution. These ten reasons are:

1. Legalization of prostitution will not be beneficial to the sex workers but for the third party which will include businessmen, brothel owners and pimps it will be like a gift to them because it will give 


\section{GAP INDIAN JOURNAL OF FORENSICS AND BEHAVIOURAL SCIENCES ( ISSN - 2582-8177)}

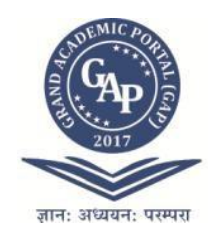

\section{SUGGESTIONS THAT CAN BE TAKEN INTO ACCOUNT TO ENCOURAGE SAFE PORNOGRAPHIC USAGE:}

1) CD's: Government can give license to companies as in to shoot and record content for the CD. Government can hire distributors for making the CDs available to the normal population, setting minimum required prices and regulating who can buy these depending on the age restrictions if necessary.

2) Subscription and password protection: Subscriptions can be provided for online websites that might be dealing with such content firsthand and cyber security features can be added to it to ensure that it isn't available to any unauthorized person. Passwords, etc

3) Identification should be mandatory: The identification details should be made mandatory which will be unique for buying the CDs so that he/she could be tracked if anything illegal happens. It can include Aadhaar number, pan card, eye scan, fingerprint security etc.

4) Applications: The similar guidelines that of website should be made for applications available on Play Store or Apple store etc

5) Review Board or Government Set-up: There should be a review board like those existing for broadcasting which can make sure that the pornographic content is recorded with the consent of the parties involved and none of it is and evidence to a crime against both women or men including instances of rape, assault, illegally recorded without the knowledge of the person or uploaded without the knowledge of the person, to prevent such instances agreements can be made that should be signed by the parties involved to give legal consent.

6) Licensing: The Websites broadcasting such contents need to have a license for the same that should be provided by the government and regular monitoring of the content should be done to prevent instances of illegal activity. There should be strict guidelines for retaining the license.

7) Cybersecurity: A Cybersecurity Personnel should be employed by the government to ensure the safety of the viewers and the actors and to decide what measures should be taken if the breach in the security occurs.

\section{REFERENCES}

[1] Babu, Y. R. (n.d.). Forensic medicine: Prep manual for undergraduates - ebook. Retrieved February 16, 2021, from https://books.google.co.in/books?id=C_HQDwAAQBAJ

[2] Chatur, D. (2009). Legalization of Prostitution in India. Retrieved February 17, 2021, from http://dcac.du.ac.in/documents/E-Resource/2020/Metrial/408RobinsonHembrom2.pdf

[3] Ciacci, R., \&Sviatschi, M. M. (2016). The effect of indoor prostitution on sex crime: Evidence from New York City. Columbia University Working Paper.

[4] Indian Kanoon. (n.d.). Section 290 and 291 of Indian Penal Code. Retrieved February 17, 2021, from https://indiankanoon.org/doc/1273321/

[5] Maes, H. R. (2012). Who Says Pornography Can't Be Art?.

[6] Mckee, Alan \& Byron, Paul \&Litsou, Katerina \&Ingham, Roger. (2020). An Interdisciplinary Definition of Pornography: Results from a Global Delphi Panel. Archives of Sexual Behavior. 49. 1-7. 10.1007/s10508019-01554-4.

[7] O'Connor, A. M. (1996). Women Working in Prostitution: Towards a healthier future. Retrieved February 09, 2021, from https://www.drugsandalcohol.ie/5616/1/2030-023Women.pdf.

[8] Pope, N. K., Voges, K. E., Kuhn, K. L., \&Bloxsome, E. L. (n.d.). Pornography and Erotica: Definitions and Prevalence. Retrieved February 9, 2021, from https://citeseerx.ist.psu.edu/viewdoc/download?doi=10.1.1.928.528\&rep=rep1\&type=pdf

[9] Rea, Michael C. (2001) 'What is Pornography?' Nous 35.1: 118-145,

[10] Annual Final Report Collection of domestic Tourism statistics for the state of Madhya Pradesh. (2003). http://tourism.gov.in/sites/default/files/Other/MP\%20Tourism\%20\%20Annual\%20Report\%20Tourism\%20Survey\%20for\%20the\%20State\%20of\%20M\%20P\%202013.pdf

[11]UNODC. (2020). Research brief: What crime and helpline data say about the impact of the COVID-19 pandemic on reported violence against women and girls. Retrieved from https://www.unodc.org/documents/data-and-analysis/covid/Violence_against_women_24Nov.pdf

[12] Van Alphen, E. (2005). 'What History, Whose History, History to What Purpose?': Notions of History in Art History and Visual Culture Studies. Journal of visual culture, 4(2), 191-202.

[13] Vijayakumar, S. (2017). The Sacred and the Sensual. Experiencing Eroticain Temples of Khajuraho. Via. Tourism Review, (11-12). 